\title{
Adaptation of Smallholder Dairy Farmers in South Western Kenya to the Effects of Climate Change
}

\section{Charles Okech Odhiambo ${ }^{*}$, Harun Okello Ogindo ${ }^{2}$, Chlirukovian Bwire Wasike ${ }^{3}$, Washington Odongo Ochola ${ }^{4}$}

\author{
${ }^{1}$ World Vision Kenya, Nairobi, Kenya \\ ${ }^{2}$ Department of Applied Plant Science, Maseno University, Kisumu, Kenya \\ ${ }^{3}$ Department of Animal Science, Maseno University, Kisumu, Kenya \\ ${ }^{4}$ Africa Lead (USAID), Nairobi, Kenya \\ Email: *charles_odhiambo@wvi.org
}

How to cite this paper: Odhiambo, C.O., Ogindo, H.O., Wasike, C.B. and Ochola, W.O. (2019) Adaptation of Smallholder Dairy Farmers in South Western Kenya to the Effects of Climate Change. Atmospheric and Climate Sciences, 9, 456-478.

https://doi.org/10.4236/acs.2019.93031

Received: May 10, 2019

Accepted: July 22, 2019

Published: July 25, 2019

Copyright $\odot 2019$ by author(s) and Scientific Research Publishing Inc. This work is licensed under the Creative Commons Attribution International License (CC BY 4.0).

http://creativecommons.org/licenses/by/4.0/

\begin{abstract}
Despite great potential, Kenyan smallholder dairying faces diminishing land sizes, high input costs, poor extension contacts, non-responsive price policies, and new pests and diseases. Climate change will worsen the situation. This study sought to assess smallholder dairy farmers' climate change adaptation level in Southwestern Kenya. Adopting Concurrent Fixed Mixed Methods, primary and secondary data was collected. Reports and papers were reviewed for temperature and precipitation data, dairy population, production trends, and farmers' socio-demographics. A survey questionnaire for climate changes and farmers' adaptiveness was administered to 367 smallholder dairy household heads with 10 years' experience, obtained by multi-stage sampling from 4 sub-counties. Key informant interviews (KIIs) and focus group discussions (FGDs) were conducted with farmer groups, heads of research, government departments and livestock farms; and the old that were obtained purposively based on dairying experience. Percentages were used for climate change effect on smallholder dairying and farmers' adaptation. Principal component analysis was used for factors with great influence on respondents' climate change adaptiveness; while one proportion Z-score test was used for significant differences between adapters and non-adapters $(p<0.05)$. Flexible and systematic Framework Approach was used for qualitative data analysis by cases and 5 themes. Findings indicated that despite Migori County's great dairying potential, climate changes have partly hindered full exploitation. Temperatures and rainfall increased slightly in 30 years; with feeds and water diminishing, and resistant diseases and parasites emerging. Upon ranking, pasture
\end{abstract}


loss (42.2\%); over-grazing (41.1\%); cattle under-feeding (39.5\%); and increasing cattle diseases and pests $(61.0 \%)$ had high impact; while drying water sources $(37.1 \%)$ had moderate effect. Farmers' adaptiveness included mixed farming (96.5\%); non-intensive dairying (95.1\%); establishing own fodder (92.4\%); rearing crossbred dairy cattle (87.7\%); reducing dairy herd size to 2 (92.9\%); relying mainly on household labour (94.6\%); and maintaining a 10 -year increasing trend in milk-income (68.4\%). Z-scores indicated significant differences between adapters and non-adopters $(\mathrm{p}<0.05)$. Civil societies, academic and research institutions should intensify farmer advisory services to complement government extension.

\section{Keywords}

Southwestern Kenya, Smallholder Dairy Farmers, Adaptive Strategies, Climate Change

\section{Introduction}

In Kenya, $75 \%$ - 90\% of the domestic milk comes from the smallholder dairy sector [1]. Smallholder dairy farming in Kenya, as in most developing countries, is practiced alongside crop production on the same farm and contributes directly and indirectly to increased livestock population and farm productivity, income generation from milk and dairy product sales, job opportunities, and the transfer of money from urban to peri-urban and rural areas [2]. Yet, most of the smallholder dairy farmers in Kenya live in marginal areas, where land sizes are increasingly diminishing, costs of agro-inputs are ever-increasing, and illiteracy and poverty force the farmers to adopt poor and archaic production methods that only lead to low yields. There is also limited extension services, which, together with non-responsive government price regulatory policies, emergence of resistant strains of pests and diseases, and pre-and post-harvest losses, lead to low financial returns on production [3]. It is for this matter that FAO recognizes "smallholder farmers" on the basis of their limited resource endowments relative to other farmers in the sector, and that the definition differs between countries and between agro-ecological zones [4].

A global trend observed in most of the marginal areas in recent decades has been a significant fall in food production, against an increasing demand for food due to high levels of population growth [5]. Global warming and the associated climate change is, therefore, expected to exacerbate the challenges smallholder dairy farmers in Kenya face, as it would lead to more crop failure and famine, with many plant and animal species having problems adapting [3]. Experts have predicted that over time, the situation will get worse [6] [7].

Thus, unless the Government and key stakeholders work together to support the Kenyan smallholder dairy farmer to adapt to effects of climate change, huge losses in terms of food production, household income and the gross domestic 
product would occur. The situation would most likely, push a number of the smallholder dairy farmers out of business; with the net result being that milk demand would greatly outweigh its production. It is in this regard that it would be important to understand how well adapted the Kenyan smallholder dairy farmer is to continue in business and even increase milk production in the advent of climate change; identify gaps and suggest measures that would help improve their adaptation to climate change effects. Therefore, this study aims to establish the climate changes that have taken place in Migori County over the past 30 years, the effects of the changes, how farmers adapt to the changes and the level of adaptation of the smallholder dairy farmers.

\section{Materials and Methods}

\subsection{Study Site}

The study was conducted in Migori County, which is located in the Southwestern Kenya between latitude $0^{\circ} 24^{\prime}$ South and $0^{\circ} 40^{\prime}$ South and Longitude $34^{\circ}$ East and $34^{\circ} 50^{\prime}$ East. The County covers an area of $2596.5 \mathrm{~km}^{2}$ including approximately $478 \mathrm{~km}^{2}$ of water surface. The County comprises eight (8) sub-counties, namely: Rongo, Awendo, Uriri, Suna East, Suna West, Nyatike, Kuria West, and Kuria East. Four sub-counties namely Rongo, Awendo, Uriri, and Kuria West were selected for the study because they present a fairly homogenous climate, which also make them the dairy belt of the County. Within the four sub-counties, the study was confined to $\mathrm{LM}_{3}$, except in Rongo, where it was undertaken in $\mathrm{UM}_{2}$.

Migori County has an inland equatorial climate modified by the effects of altitude, relief and the influence of the large body of water of Lake Victoria. Rainfall is generally continuous with little distinction between first and second rains. Annual rainfall averages between $700 \mathrm{~mm}$ and $1800 \mathrm{~mm}$ [8]. The first peak season comes over the months of March to May, and is reminiscent of the long rainy season; while the second peak season that is reminiscent of the short rains comes over the period of September-November. The two peaks are separated by a three month period each, of June-August and December-February; when there is rainfall, but the amounts are low compared to the rest of the months. On average February is generally considered the driest month, while April is the wettest month. Temperatures show mean minimum of $24^{\circ} \mathrm{C}$ and maximum of $31^{\circ} \mathrm{C}$, with high humidity and a potential evaporation of $1800 \mathrm{~mm}$ to $2000 \mathrm{~mm}$ per year.

As in most parts of Kenya, the amounts of precipitation received in Migori County over the short rainy seasons has been on the increase, sometimes even being more reliable, well distributed and higher in amounts and spread (spatial and temporal) compared to the long rainy seasons [9]. This implies that the major issue around Migori County is coping with increased amounts of precipitation and higher temperatures. The result could be disappearance of some crop and livestock species; reduced forage amounts and variability for livestock; and 
emergence of new species and strains of crop and livestock diseases and pests that may prove difficult to manage. Overall, there would be reduced returns from livestock rearing; and, difficulties in getting the right cultivars and livestock breeds that would adapt to that kind of climate and remain in production under such harsh conditions.

In the four sub-counties of study, smallholder dairying is more prominent in Rongo, Awendo, Uriri and Kuria West, in that order. Although Kuria East and West present favourable climate for dairying, cattle rustling has remained a great impediment to the development of the dairy industry therein [10].

With a human population of 917,170 people (2009 Census), and each person requiring 1 cup (or $300 \mathrm{ml}$ ) of milk daily [11]; Migori County is generally a milk deficit county, having to subsidize its milk production with imports from neighbouring counties, such as Kisii, Nyamira, and Bomet, as processed milk that is retailing in most outlets within the county.

The study was conducted among smallholder dairy farmers whose average land holding size is 3 acres, practice mixed crop and dairy farming, and have been in dairying for at least 10 years. Milk from the industry is consumed within the household, while some of it is sold locally for income. Whereas a number of the smallholder dairy farmers make significant investments in the dairy industry to improve production and income, several others largely practice semi-intensive dairying (keeping dairy cattle in stalls, mainly during the night and milking times, while tethering them the rest of the time). Characteristically the smallholder dairy farmers of the study area keep cross-bred cattle, and depend largely on fodder from own farm, while a few lease land for fodder production or buy it from neighbours. Most of the smallholders depend on water from the rivers, such as Kuja, Migori, Riana, Ongoche, and Sare. While some have sunk shallow wells for watering the dairy cattle and for domestic use, others supplement with rain water harvesting (mainly in the form of roof catchment).

\subsection{Study Population and Sampling}

The population of the four sub-counties was estimated to be 608,372 persons as of 2012 (based on 2009 Census), with an average household size of 5 and a dairy population of 7081. Of this population, 2528 were smallholder dairy farmers; from whom a representative sample of 367 households was drawn for the study. This sample was based on formula by Yamanne [12] for determining sample sizes for population less than 10,000 as presented in the following equation:

$$
n=\frac{N}{1+N(e)^{2}}
$$

where:

$$
\begin{aligned}
& n=\text { the desired sample size (for target populations less than 10,000); } \\
& N=\text { the population size; } \\
& e=\text { the level of precision or statistical significance set. }
\end{aligned}
$$

Therefore, given that the population of smallholder dairy farmers in the se- 
lected agro-ecological zones $\left(\mathrm{UM}_{2}\right.$ and $\left.\mathrm{LM}_{3}\right)$ of study within Migori County was 2528 , for measurement at $\mathrm{p}<0.05$, the desired sample size was:

$$
n=\frac{2528}{1+2528(0.05)^{2}}=345.355 \quad(\approx 345 \text { smallholder dairy farmers })
$$

Considering an additional $10 \%$ for non-respondents (i.e. $\approx 35$ ), the desired sample size for this study was 380 smallholder dairy farmers.

Due to difficulties in covering all the sampled households in parts of Kuria West, largely as a result of insecurity, the study was conducted among 367 smallholder dairy farmer households distributed among the four sub-counties as shown in Table 1.

Multi-stage sampling was used to obtain the sample. First, a visit was made to the sub-county livestock offices, from which a listing of all smallholder dairy farmers in each of the wards was obtained. Then, proportions of farmers in each of the wards were determined based on the populations listed. The same were used to distribute the required sample size (367) within each of the wards.

Within each ward, the number of villages where smallholder dairying was being practiced was determined and proportionate sampling was again used to assign the number of farmers per village. Within each village, simple random sampling was used to pick households for inclusion into the study.

On the other hand, for qualitative study, participants were identified and picked by purposive sampling, based on their role and level of involvement in smallholder dairying and meteorology.

\subsection{Data Collection Methods}

Both primary and secondary data were collected. Secondary data was obtained by review of reports and documents and from literature obtained from the internet and from government offices, research stations (KALRO and Meteorological Department) using a data checklist. The data collected included dairy population of the four sub-counties of study as well as socio-demographic and dairy production profiles of smallholder farmers within the study area. Other secondary data collected included temperature and precipitation data, as well as trends in milk production, demand and sales in the four sub-counties of study.

Table 1. Sample size for the study.

\begin{tabular}{cccc}
\hline Sub-County & $\begin{array}{c}\text { Number of Smallholder } \\
\text { Dairy Farmers }\end{array}$ & Desired Sample Size & Actual Sample Size \\
\hline Rongo & 1480 & 222 & 232 \\
Awendo & 88 & 13 & 13 \\
Uriri & 510 & 77 & 77 \\
Kuria West & 450 & 68 & 45 \\
Total & 2528 & 380 & 367
\end{tabular}


Primary data collection included both quantitative and qualitative data. A structured household survey questionnaire was used to obtain primary quantitative data from heads of smallholder dairy households with at least 10 years' experience in dairying. The questionnaire solicited data on smallholder dairy farmers' adaptive strategies to climate change effects. On the other hand, key informant interview (KII) and focus group discussion (FGD) guides were used to collect primary qualitative data from individuals and groups perceived to be experts and opinion leaders on climate change.

Key informants included heads of key government parastatals and departments (of meteorology, environment, livestock production, cooperatives, and key government livestock production farms), leadership of a dairy cooperative society and dairy farmer groups, and climate change livestock research experts from Kenya Agriculture and Livestock Research Organization (KALRO)-Kisii Station.

Focus group discussions were conducted with elders (men and women) aged over 60 drawn from Kuria and Luo communities in Migori County; members of Rongo Dairy Farmers' Cooperative Society, and select dairy farmer groups in Migori County.

The proceedings of KIIs and FGDs were recorded using a digital recorder and transcribed verbatim after listening to the recordings several times. A research note book was only used to note cues for reference.

In addition, Non-participant Observation was used to collect additional information for the study. An observation guide was prepared and used to facilitate the recording of information. The information was collected using a camera, recorder, and by note-taking. Visits were made to the smallholder dairy farmers' households and homesteads, and dairy cooperative societies to record their activities that may be useful in providing further insights into the matter under investigation. This was complimented by transect walks over the sub-counties to provide an overview of the smallholder dairy industry in Migori County. Photographs of live events were taken during the study; including the enumeration process, focus group discussions, farm activities undertaken by smallholder dairy farmers, and evidence of climate change in the study communities, including land degradation and formation of gullies.

\subsection{Data Collection}

Data collected using the household survey questionnaire included the respondents' adaptive strategies to climate change effects. The questionnaire sought to establish the problems the smallholder dairy farmers faced in trying to adapt to climate changes, and whether the identified climate change effects had high, medium or low effect. Multiple responses were allowed. It also sought to understand the respondents' adaptive strategies to climate change effects, which was defined by:

1) The farming type adopted (whether mixed dairy and crop or pure dairy farming); 
2) The production method employed (whether intensive or non-intensive);

3) The major source of fodder (whether own or purchased);

4) The type of breeds kept (whether pure or non-pure);

5) Dairy breeds kept (whether Friesian and its crosses, or Non-Friesians and their crosses);

6) The number of dairy cattle kept (Whether 2 and above, or not);

7) The main source of farm labour (whether household or non-household); and

8) The observed trend in income from dairying (whether increasing or decreasing trend from milk sales).

Further, the questionnaire sought to understand the smallholder dairy farmers' reasons for adopting these adaptation strategies and their level of satisfaction with farm labour and observed trend in monthly income from sale of milk from dairy cattle.

KII and FGD guides collected personal information about the individual and group respondents. The guides sought to establish respondents' perceptions on changes in temperature and precipitation as a measure of climate changes taking place in Migori County over the past 15 years. It also sought to understand the impact of the changes on smallholder dairy industry in the study area; how the smallholder dairy farmers of the study area were trying to cope with them; and the challenges they were facing as they tried to adapt.

\subsection{Data Transcription and Analysis}

Quantitative data obtained from the survey was organized into percentages to show the effects of climate changes on smallholder dairying and the adaptive strategies employed by study respondents to climate change effects. The data was then subjected to a principal component analysis (PCA), where 8 factors were identified to have the potential of influencing smallholder dairy farmers' adaptation to climate change effects (i.e. mixed farming, non-intensive production system, own fodder, non-pure breed of dairy cattle, non-Friesians and their crosses, 2 dairy cattle and above, household is main source of labour, and increasing trend in income from dairying). The first three factors that had the highest proportionate influence, based on the Eigen values were then determined. Finally, one proportion Z-score test for proportions was used to test for significant difference between the means of the climate change adaptation measures and the presumed mean (assuming that $50 \%$ of respondents would adapt and the other $50 \%$ would not), so as to confirm if the differences were significant $(\mathrm{p}<0.05)$ as per the equation below:

$$
Z_{i}=\frac{\chi_{i}-\chi}{s}
$$

where;

$$
\begin{aligned}
& Z_{i}=\mathrm{Z} \text {-score for an attribute } i ; \\
& \chi_{i}=\text { observed mean for an attribute } i ;
\end{aligned}
$$




\section{$\chi=$ sample mean;}

$s=$ sample standard deviation.

Qualitative data (KIIs and FGDs) was first transcribed from the voice recordings into word. The word version was then entered into an excel spread sheet and analysed using the Framework Approach. This approach is used to organize and manage data by summarization, resulting in a robust and flexible matrix output, which allows for analyzing data both by case and themes. In the analysis, data is sifted, charted and sorted in accordance with key issues and research themes using five steps: familiarization; identifying a thematic framework; indexing; charting; and mapping and interpretation.

\section{Results}

\subsection{Findings from Desktop Review/Secondary Data}

Table 2 presents a summary of the dairy population of Migori County by sub-county.

Records from the four sub-counties of study indicate that Migori County has a great potential in terms of dairy production and earnings from the same. Table 3 gives a summary of this, based on 2012 Annual Reports from the four sub-counties of Rongo, Awendo, Uriri, and Kuria West.

Table 2. Dairy population of Migori County-Kenya.

\begin{tabular}{ccc}
\hline Sub-County & \multicolumn{3}{c}{ Dairy Population } \\
\cline { 2 - 4 } & Dairy Cattle & Dairy Goats \\
\hline Migori (Suna West \& East) & 2569 & 160 \\
Uriri & 1941 & 1333 \\
Awendo & 667 & 929 \\
Rongo & 3765 & 1194 \\
Nyatike & 780 & 180 \\
Kuria West & 1199 & 153 \\
Kuria East & 659 & 84 \\
Total & 11,580 & 4033 \\
\hline
\end{tabular}

Source: GoK, 2013b. Adapted from Migori County ASDSP Revised Livestock Development Plan, 2013.

Table 3. Summary of demographics and dairy production in selected sub-counties of Migori.

\begin{tabular}{cccccccc}
\hline Sub-County & $\begin{array}{c}\text { Area } \\
\left(\mathrm{Km}^{2}\right)\end{array}$ & $\begin{array}{c}\text { Human Population } \\
\mathbf{( 2 0 0 9 )}\end{array}$ & $\begin{array}{c}\text { Farm } \\
\text { Families }\end{array}$ & $\begin{array}{c}\text { Av. } \\
\text { Family Size }\end{array}$ & $\begin{array}{c}\text { Dairy Population } \\
\mathbf{( 2 0 1 2 )}\end{array}$ & $\begin{array}{c}\text { Milk Production } \\
\text { in Litres (2012) }\end{array}$ & $\begin{array}{c}\text { Earnings from Milk } \\
\text { Sales in Kshs. (2012) }\end{array}$ \\
\hline Rongo & 208.5 & 209,460 & 23,063 & 5 & 3274 & $11,587,625$ & $463,505,000$ \\
Awendo & 264 & 108,908 & 24,000 & 6 & 667 & $3,360,000$ & $120,267,800$ \\
Uriri & 380.7 & 115,751 & 23,150 & 5 & 1941 & $2,427,790$ & $145,667,400$ \\
Kuria West & 390 & 174,253 & 21,243 & 6 & 1199 & $9,066,228$ & $362,649,120$ \\
Total & $\mathbf{1 2 4 3 . 2}$ & $\mathbf{6 0 8 , 3 7 2}$ & $\mathbf{9 1 , 4 5 6}$ & $\mathbf{5}$ & $\mathbf{7 0 8 1}$ & $\mathbf{2 6 , 4 4 1 , 6 4 3}$ & $\mathbf{1 , 0 9 2 , 0 8 9 , 3 2 0}$ \\
\hline
\end{tabular}

Source: Adapted from GoK, 2012a-e. District Livestock Production Department Annual Reports (2012) for Rongo, Awendo, Uriri, Migori and Kuria West sub-counties. 
Moreover, secondary data indicates that the entire County has a milk deficit, with Rongo sub-county producing only about 11.59 Million litres in 2012, while the demand stood at 30 Million litres; making Rongo Dairy Cooperative Society operate below its capacity. The sub-county had to meet the deficit of $18.41 \mathrm{Mil}-$ lion litres by importing packed milk from New KCC and Brookside Dairies. Raw milk from neighbouring sub-counties and counties also find its way into the sub-county. A litre of milk is sold at Kshs. 40 on average in the sub-county in 2012 [13].

In 2012, most of the milk in Awendo sub-county was produced from zebu cattle, with dairy population expected to improve following the efforts by Pan African Tsetse and Trypanosomiasis Eradication Campaign (PATTEC)-Kenya that begun to give dairy cattle to dairy farmer groups within the sub-county [14]. In 2012, the milk requirement for Uriri sub-county stood at approximately 10.6 Million litres; with only 2.4 Million litres being produced within the county. This left a deficit of 8.2 Million litres, forcing the sub-county to import milk from the neighbouring sub-counties; with a litre of raw milk retailing at Kshs. 40 - 60. Thus, a great opportunity exists to promote the dairy industry in the sub-county to create a source of livelihood and income for the populace, thereby making a contribution to the country's GDP. Nevertheless, challenges, including prevalence of tick-borne diseases and prevalence of tsetse flies (which could be exacerbated by effects of climate change); as well as lack of quality breeding stock and long calving intervals, have to be tackled effectively if this is to be realized [15].

With a human population of 191,248 people (2009 Census), and each person requiring $300 \mathrm{ml}$ of milk daily; Migori sub-county has an annual milk requirement of 20,941,656 litres. Yet, in 2012, the annual milk production for the sub-county stood at 1,528,901.4 litres; giving a deficit of about 19,412,754.6 litres. Most of the milk consumed in the sub-county comes from the neighbouring sub-counties, as well as from processing companies; with a litre of raw milk retailing at Kshs. 50 [16]. Key challenges to developing the dairy sector in the sub-county include high cost of purchasing quality breeding stock, supplementary feeds, A.I., and veterinary drugs; inadequate farmer extension and advisory services, limited supplies of reliable quality dairy inputs by local stockists, limited access to financial services, and limited land for raising own feeds and fodder due to excessive land sub-division.

According to Kuria West sub-county Department of Livestock Production Annual Report (2012), the dairy sector is not well developed in the sub-county. Major challenges identified included: long distance to the nearest sources of quality breeding stock, high start-up capital for the dairy enterprises, cattle rustling, ignorance from local community, which also shuns labour-intensive activities, negative cultural beliefs and attitudes, high cost of A.I. service, and few bull schemes within the sub-county. The most serious threat to the growth of the sector, however, remains theft of dairy cattle [17]. Generally, most of the 
dairy breeding stocks within the county come from Nakuru, Kisii, Nyamira, Kericho, and Uashin Gishu counties. Some are sourced internally, from one sub-county to another, e.g. from Rongo to Uriri, Awendo, Migori, and Kuria West sub-counties [17].

\subsection{Evidence of Climate Changes and Their Impact}

Figure 1 presents temperature data from the study area for 35 years (1982-2015).

Figure 1 shows that generally there has been an increase of at least $1^{\circ} \mathrm{C}$ in minimum temperature of the study area between 1982 and 2015. The same trend seems to be registered in terms of average temperature. As for maximum temperature, the figure shows that this has increased slightly from $28.2^{\circ} \mathrm{C}$ in 1982 to $28.5^{\circ} \mathrm{C}$ in 2015 , although higher increases were experienced in-between.

Figure 2 shows that the mean annual rainfall $(\mathrm{mm})$ received in Migori County fluctuated over the period 1980-2013, but have generally shown a slight increment over the period.

Secondary data obtained from Lake Victoria Observing System (LVOS) further indicate that rainfall amounts have been steadily increasing in the region of Migori since 1980s to-date. This has resulted into floods along the flood basins of Rivers Migori and Kuja. Consequently, hundreds of local residents, especially

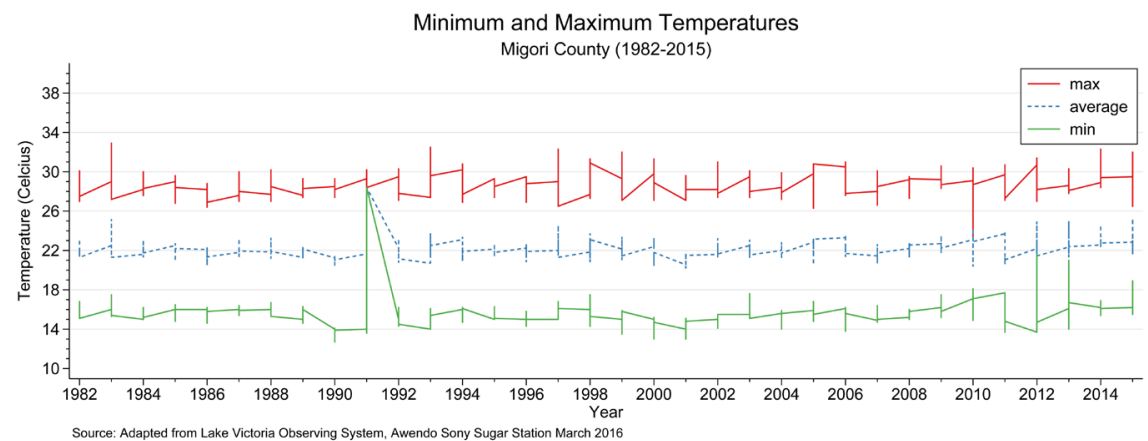

Figure 1. Temperature variations for Migori County (1982-2015).

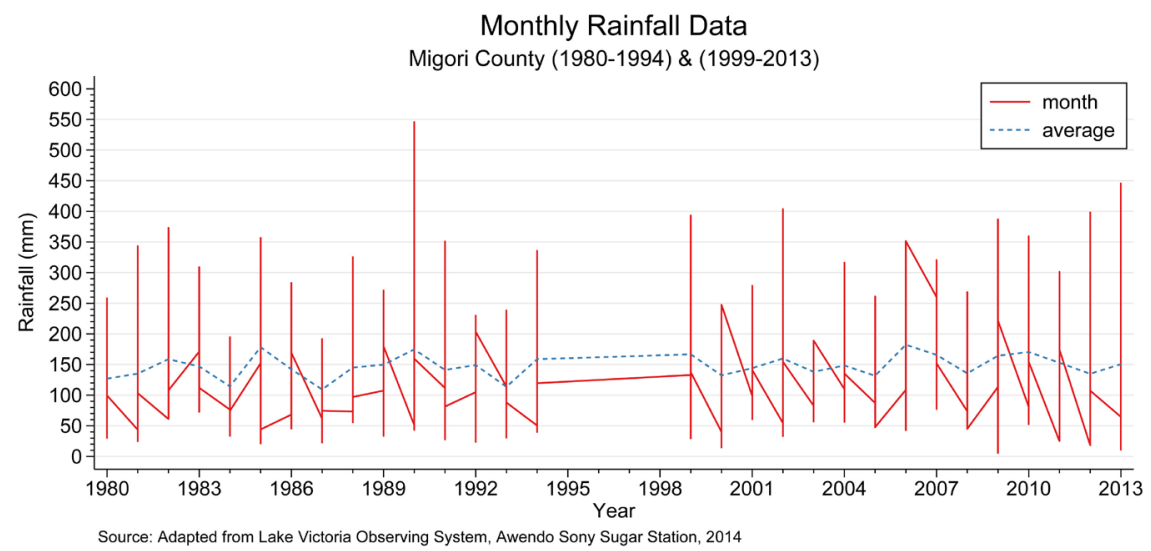

Figure 2. Changes in rainfall for Migori County (1980-2013). 
within Nyatike Sub-county, have been displaced almost annually over the long rainy seasons since the year 2000 .

LVOS, a local CBO based in Rapogi in Uriri sub-county of Migori County reported on rainfall data collected for 15 years (1980-1994) from Rapogi D.O.'s Office, Awendo Sony Sugar Factory, and Kisii's KALRO Weather Station. The emerging rainfall pattern is that of rainfall throughout the year, with two peaks from March to May and August to November. Further, the pattern indicates that the area has not suffered from any serious drought, apart from rainfall distortions [18].

What is emerging in Migori County, as in most parts of Kenya; is that the amounts of precipitation received over what has been traditionally known as short rainy seasons has been on the increase, sometimes even proving to be more reliable, well distributed and higher in amounts and spread (spatial and temporal) compared to the long rainy seasons [9].

This implies that the major issue around Migori County is coping with increased amounts of precipitation and higher temperatures. These could lead to disappearance of some crop and livestock species, hence; reduced forage amounts and variability for livestock. Besides, there is a likelihood of emergence of new strains of crop and livestock diseases and pests that may be difficult to manage. This would ultimately lead to reduced returns on investment from livestock rearing. There would also be the challenge of getting the right cultivars and livestock breeds that would adapt to that kind of climate and remain in production under such harsh conditions.

The study established from discussion with elders (over 60 years of age) that both day and night temperatures used to be colder in the 1960s and 1970s than today. The elders put the blame on increasing human settlement and farming activities, which have seen more trees cut down. The reduction in tree cover has seen a remarkable increase in day and night temperatures, which has meant that during the day, people would rarely cover themselves with heavy jackets like before. Likewise, in the night, people would rarely cover themselves with heavy blankets, like Raymond's that was popular in those days. The increase has been very steady and presenting a direct proportionality with time, more so since the year 2000. Interview with Migori County Director for Meteorological Services confirmed that temperatures have been steadily increasing with time, with a global increase of $0.3^{\circ} \mathrm{C}$ being registered.

The study further established from focus group discussants that increases in temperature have largely contributed to changes in rainfall patterns, hence; climate change. This is because the main driver of seasons is solar energy, such that with climate change there is differential heating of the water bodies and the earth surface. Through the water bodies we get water vapour, hence; there is a relationship between temperature and climate change.

Engagements with focus group discussants, both elders and dairy farmer groups, indicated that the total amount of rainfall has more or less remained constant, comparing the 60 's and today. What have changed are the distribution 
and the rainfall patterns. Rainfall in those days used to have distinct seasons-long rains and short rains, with long rains coming from January to May; while short rains would be experienced between September and November. Today, long rains are experienced between March and May, while short rains come between October and December. These findings were further corroborated by the County Director of Meteorological Services.

Long rains were generally higher in amounts compared to short rains, and would rain for 2 - 3 hours in the morning, and another 2 - 3 hours in the afternoon and/or the night; while short rains would generally come mainly in the afternoon. Today, onset of the rainy seasons is not very predictable, just like the duration and amounts. Sometimes, long rains delay and begin as late as May, and end in a month or so time; with the amount received in a period of three weeks being almost equal to what would in the early days be received in 3 months' time. Sometimes, the long rains would continue, with another season bridging between the long and short rainy seasons, such that rainfall would somehow be continuous throughout the year. A remarkable change is that sometimes more rain is received during the short rainy season than the long rainy season.

Today, unlike in the days of 60's and 70's, rainfall distribution (temporal and spatial) is also very erratic, although the intensity has generally been increasing. Rainfall amounts vary from area to area, creating micro-climatic differences within the County and even within individual sub-counties, although an increasing trend has been noted.

These changes both in temperature and rainfall patterns have their direct and/or indirect effects on smallholder dairy farming. The study sought to understand the climate change effects experienced by smallholder dairy farmers in Migori County-Kenya, and to establish the adaptive strategies adopted by farmers in response to the same. Table 4 presents the findings.

The study established that climate changes have moderate to high effects on the performance of the smallholder dairy industry within the County. The survey established that climate changes with high effects experienced by smallholder dairy farmers in Migori County include: increase in diseases and pests $(61.0 \%$; $\mathrm{n}=367)$; pasture loss $(42.2 \%$; $\mathrm{n}=367)$; over grazing of land $(41.1 \%$; $\mathrm{n}=367)$; and under feeding of livestock $(39.5 \% ; \mathrm{n}=367)$. Those with moderate effect include: increased labour demand $(42.2 \% ; \mathrm{n}=367)$; poor quality products $(41.1 \%$; $\mathrm{n}=367)$; reduced milk production $(38.7 \%$; $\mathrm{n}=367)$; drying of nearest water sources $(37.1 \% ; n=367)$; water scarcity $(36.8 \% ; n=367)$; and loss of livestock $(35.1 \% ; \mathrm{n}=367)$.

\subsection{Smallholder Dairy Farmers' Adaptive Strategies to Climate Change Effects}

The study further sought to establish the adaptive strategies the smallholder dairy farmers employed in order to cope with the climate change effects. Findings are presented in Figure 1 that shows the extent to which each of the eight 
Table 4. Climate change effects on smallholder dairy farming in Migori County $(\mathrm{n}=$ 367).

\begin{tabular}{|c|c|c|c|c|c|c|c|c|}
\hline \multirow{2}{*}{ Climate Change Effect } & \multicolumn{2}{|c|}{ No Effect } & \multicolumn{2}{|c|}{ Low Effect } & \multicolumn{2}{|c|}{ Moderate Effect } & \multicolumn{2}{|c|}{ High Effect } \\
\hline & No. & $\%$ & No. & $\%$ & No. & $\%$ & No. & $\%$ \\
\hline Pasture loss & 35 & 9.5 & 95 & 25.9 & 82 & 22.3 & 155 & 42.2 \\
\hline Drying of nearest water sources & 32 & 8.7 & 97 & 26.4 & 136 & 37.1 & 102 & 27.8 \\
\hline Loss of livestock & 86 & 23.4 & 81 & 22.1 & 129 & 35.1 & 71 & 19.3 \\
\hline Under feeding of livestock & 15 & 4.1 & 82 & 22.3 & 125 & 34.1 & 145 & 39.5 \\
\hline Increases in diseases and pests & 6 & 1.6 & 42 & 11.4 & 95 & 25.9 & 224 & 61.0 \\
\hline $\begin{array}{l}\text { Selling of livestock } \\
\text { at throw away prices }\end{array}$ & 107 & 29.2 & 62 & 16.9 & 114 & 31.1 & 84 & 22.9 \\
\hline $\begin{array}{l}\text { Long walk in search } \\
\text { of water and pasture }\end{array}$ & 101 & 27.5 & 120 & 32.7 & 123 & 33.5 & 23 & 6.3 \\
\hline Over grazing of land & 18 & 4.9 & 85 & 23.2 & 113 & 30.8 & 151 & 41.1 \\
\hline $\begin{array}{l}\text { Poor market for the livestock } \\
\text { products due to poor quality }\end{array}$ & 18 & 4.9 & 74 & 20.2 & 151 & 41.1 & 124 & 33.8 \\
\hline More human labour required & 20 & 5.4 & 56 & 15.3 & 155 & 42.2 & 136 & 37.1 \\
\hline $\begin{array}{c}\text { Increase in } \\
\text { livestock-human-wildlife conflict }\end{array}$ & 69 & 18.8 & 101 & 27.7 & 118 & 32.2 & 79 & 21.5 \\
\hline Reduced milk production & 36 & 9.8 & 107 & 29.2 & 142 & 38.7 & 82 & 22.3 \\
\hline Water scarcity & 43 & 11.7 & 59 & 16.1 & 135 & 36.8 & 130 & 35.4 \\
\hline
\end{tabular}

parameters for measuring adaptation to climate change was adopted by the study farmers. Multiple responses were accepted.

From Figure 3, it is evident that the smallholder dairy farmers of Migori County are highly adapted to climate change effects; with $68.4 \%$ to $96.5 \%$ of them adopting various strategies in response to climate change effects. Majority $(96.5 \% ; \mathrm{n}=367)$ of the smallholder dairy farmers practice mixed crop and dairy farming as an adaptive strategy to climate change effects, with $95.1 \%(\mathrm{n}=367)$ adopting non-intensive production methods that largely involve integration of zero-grazing with tethering of the cattle, and sometimes free range grazing in enclosed fields without mixing the cattle with other livestock. Majority (92.4\%) of the study respondents $(n=367)$ indicated that they depended on fodder from their own farms; with $87.7 \%(n=367)$ rearing non-pure breeds of dairy cattle that are mainly crosses of Ayrshires, with some Guernseys and/or Jerseys. Majority $(92.9 \%)$ of the study respondents $(n=367)$ keep at least 2 dairy cattle or their crosses, with household members providing the main source of labour for $94.6 \%$ of the study respondents $(n=367)$. Slightly over half $(68.4 \%)$ of the study respondents $(n=367)$ registered an increase in income from milk sales over the past 10 years.

The study established that a comparatively low number of farmers registered increases in income from milk sales over the past 10 years. This is a pointer to tough economic times making consumers change feeding patterns, hence; low 


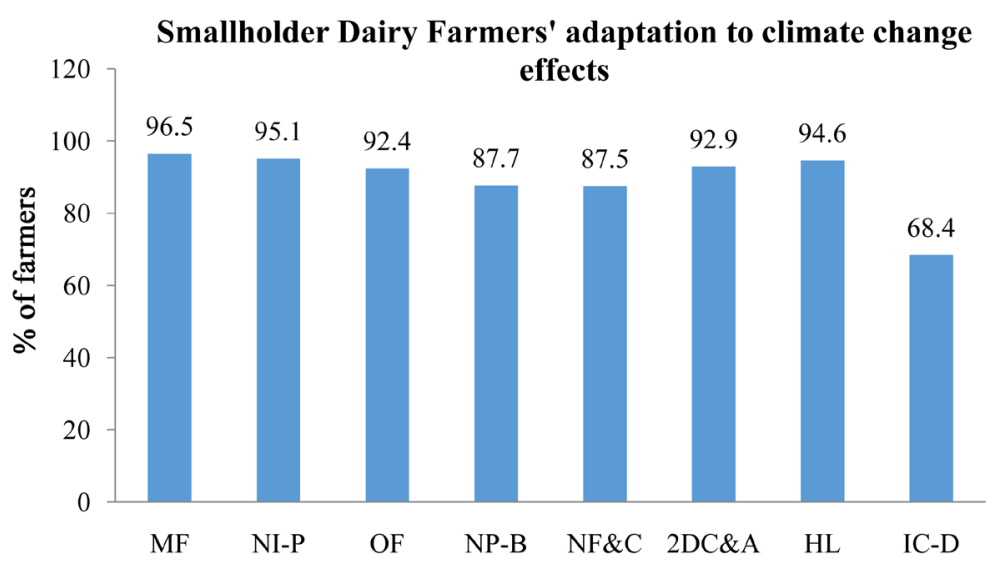

Figure 3. Distribution of respondents by climate change adaptive strategies employed (n = 367; multiple responses accepted). MF: Mixed Farming; NI-P: Non intensive production; OF: Own Fodder; NP-B: Non Pure Breeds if dairy cattle; NF\&C: Non Friesian breeds and their Crosses; 2DC \& A: 2 Dairy Cattle and Above (i.e. at least 2 dairy cattle); HL: Household Labour; IC-D: Increasing trend in household Income from Dairying.

milk demand; and high cost of inputs (notably feeds and treatment for diseases and parasites).

\subsubsection{Principal Component Analysis (PCA)}

Eigen values and the respective proportions accounted for by the various adaptive factors from Principal Component Analysis (PCA) are presented in Table 5. The factors included Mixed Farming (Factor 1); Non-intensive production system (Factor 2); Own fodder (Factor 3); Non pure breed of dairy cattle (Factor 4); Non Friesians and their crosses (Factor 5); 2 dairy cattle and above (Factor 6); Household is main source of labour (Factor 7); and Increasing trend in income from dairying (Factor 8).

Table 5 presents the findings.

From Table 5, three (3) factors, Mixed farming (Factor 1), Non intensive production system (Factor 2) and Own fodder (Factor 3) are great determinants of adaptability of smallholder dairy farmers to climate change (having highest Eigen values). Thus, smallholder dairy farmers who practice mixed farming, non-intensive production system, and have established own source of fodder for feeding the cattle are better adapted to climate change effects than their counterparts who have not.

A Factor Loading Matrix was used to determine the uniqueness of the combination of the various sets of adaptive strategies employed by smallholder dairy farmers. Results are presented in Table 6.

Table 6 indicates that Non intensive production system (Factor 2) was the highest predictor for choice of farming type adopted by the study respondents, as well as decision to establish own-farm fodder for the dairy cattle. Similarly, Mixed farming (Factor 1) was the highest predictor of production system employed, the breed of dairy cattle kept, and a decision to rear breeds of cattle that are highly adapted to the environment by the study respondents. Own fodder 
Table 5. Eigen values and the relative contribution of the adaptive factors to climate change adaptability.

\begin{tabular}{ccccc}
\hline Factor & Eigen value & Difference & Proportion & Cumulative \\
\hline Mixed farming & 1.934 & 0.662 & 0.242 & 0.242 \\
Non intensive production system & 1.272 & 0.254 & 0.159 & 0.401 \\
Own fodder & 1.017 & 0.096 & 0.127 & 0.528 \\
Non pure breed of dairy cattle & 0.921 & 0.025 & 0.115 & 0.643 \\
Non Friesians and their crosses & 0.896 & 0.083 & 0.112 & 0.755 \\
2 dairy cattle and above & 0.813 & 0.143 & 0.102 & 0.856 \\
Household is main source of labour & 0.670 & 0.193 & 0.084 & 0.940 \\
Increasing trend in income from dairying & 0.478 & & 0.060 & 1.000 \\
\hline
\end{tabular}

LR Test: independent vs saturated. $\mathrm{Chi}^{2}(28)=226.08$; Prob. $>\mathrm{Chi}^{2}=0.00$.

Table 6. Interaction of key determinant factors with adaptation variables in determining climate change adaptation.

\begin{tabular}{|c|c|c|c|c|}
\hline Variable & $\begin{array}{l}\text { Mixed } \\
\text { farming }\end{array}$ & $\begin{array}{c}\text { Non intensive } \\
\text { production system }\end{array}$ & $\begin{array}{l}\text { Own } \\
\text { fodder }\end{array}$ & Uniqueness \\
\hline Farming type & 0.387 & 0.393 & -0.167 & 0.668 \\
\hline Production system & 0.650 & 0.202 & -0.168 & 0.509 \\
\hline Source of fodder & -0.202 & 0.574 & 0.174 & 0.6 \\
\hline Breed of dairy cattle kept & 0.779 & -0.071 & 0.101 & 0.378 \\
\hline $\begin{array}{c}\text { Adaptability of cattle } \\
\text { breeds to local conditions }\end{array}$ & 0.798 & 0.109 & 0.007 & 0.352 \\
\hline Number of dairy cattle kept & 0.152 & 0.009 & 0.879 & 0.204 \\
\hline Main source of farm labour & 0.148 & -0.603 & 0.274 & 0.539 \\
\hline Income trend from dairying & -0.184 & 0.605 & 0.270 & 0.527 \\
\hline
\end{tabular}

(factor 3) was the highest predictor of the number of dairy cattle kept by the study respondents.

Thus, the study established that smallholder dairy farmers who chose to go for non-intensive dairying were about $40 \%$ more likely to adopt mixed farming, and about $60 \%$ more likely to establish own-farm fodder. Those that opted for mixed farming were about $70 \%$ more likely to practice non-intensive dairying; about $80 \%$ more likely to keep cross breeds of dairy cattle, and about $80 \%$ more likely to rear non-Friesian breeds and their crosses that are considered more adaptable to the climatic conditions of the study area. On the other hand, the smallholder dairy farmers who had established fodder own farm were about $90 \%$ more likely to rear at least 2 dairy cattle.

Table 6 further indicates that in terms of uniqueness, $66.8 \%$ of the variance in farming type is not shared with other variables in the overall factor model. On the contrary, the number of dairy cattle kept has low variance not accounted for by other variables, being $20.41 \%$. This impulse that the number of dairy cattle 
kept is a strong predictor of adaptability of smallholder dairy farmers in the study area.

Table 7 presents results of rotated factor loadings for correlations (based on the assumption that the factors are not correlated to each other) and for ease of interpretation.

From Table 7, all the three factors (1, 2 and 3) combined account for $52.78 \%$ of the total variance observed. From Table 7, it is further observed that Mixed Farming (Factor 1) could predict smallholder dairy farmers' choice of farming type to be adopted by $49.6 \%$; production system to practice by about $69.5 \%$; breed of dairy cattle to keep by about $71.4 \%$; and consideration of the adaptability of the breed to the local environment by about $79.1 \%$. On the other hand, Non-intensive production system (Factor 2) could predict smallholder dairy farmers' consideration of the source of fodder for the dairy herd by about $62.7 \%$; and the trend in income from sale of milk from the dairy herd by about $67 \%$. Own fodder (Factor 3) could predict smallholder dairy farmers' choice of number of dairy cattle kept by about $88.2 \%$; and a consideration of the main source of farm labour (whether household or non-household) by about $37.6 \%$.

To find out which factors are related to the adaptive strategies employed by the smallholder dairy farmers in the study area, a prediction matrix was plotted and results presented in Table 8.

Table 7. Inter-factor correlations in determining climate change adaptation.

\begin{tabular}{|c|c|c|c|c|}
\hline \multicolumn{5}{|c|}{ Orthogonal Factor Loading based on Kaiser Guttman Correlation } \\
\hline Factor & Variance & Difference & Proportion & Cumulative \\
\hline Mixed farming & 1.87334 & 0.5686 & 0.2342 & 0.2342 \\
\hline Non intensive productive system & 1.30474 & 0.26033 & 0.1631 & 0.3973 \\
\hline Own fodder & 1.04441 & & 0.1306 & 0.5278 \\
\hline \multicolumn{5}{|c|}{ Pattern Matrix } \\
\hline Variance & $\begin{array}{l}\text { Mixed } \\
\text { farming }\end{array}$ & $\begin{array}{c}\text { Non intensive } \\
\text { production system }\end{array}$ & Own fodder & Uniqueness \\
\hline Farming type & 0.4955 & 0.2483 & -0.1582 & 0.6678 \\
\hline Production system & 0.6946 & 0.0004 & -0.0913 & 0.5092 \\
\hline Source of fodder & -0.0568 & 0.6272 & 0.0581 & 0.6 \\
\hline Breed of dairy cattle kept & 0.7137 & -0.2438 & 0.2299 & 0.3783 \\
\hline $\begin{array}{c}\text { Adaptability of cattle } \\
\text { breeds to local conditions }\end{array}$ & 0.7911 & -0.0939 & 0.1154 & 0.352 \\
\hline Number of dairy cattle kept & 0.0483 & 0.1261 & 0.8819 & 0.2041 \\
\hline Main source of farm labour & -0.0531 & -0.5631 & 0.3759 & 0.5389 \\
\hline Income trend from dairying & -0.042 & 0.6697 & 0.1502 & 0.5272 \\
\hline \multicolumn{5}{|c|}{ Factor Rotation Matrix } \\
\hline & Factor 1 & Factor 2 & \multicolumn{2}{|c|}{ Factor 3} \\
\hline Mixed farming & 0.9559 & -0.2493 & \multicolumn{2}{|c|}{0.1556} \\
\hline Non intensive production system & 0.2712 & 0.9522 & \multicolumn{2}{|c|}{-0.1405} \\
\hline Own fodder & -0.1131 & 0.1765 & \multicolumn{2}{|c|}{0.9778} \\
\hline
\end{tabular}


Table 8. Predictability of adaptability of smallholder dairy farmers to climate change.

\begin{tabular}{cccc}
\hline Variable & Mixed farming & $\begin{array}{c}\text { Non intensive } \\
\text { production system }\end{array}$ & Own fodder \\
\hline Farming type & $\mathbf{0 . 2 9 3 7 4}$ & 0.21549 & -0.17272 \\
Production system & 0.38276 & 0.03811 & -0.13126 \\
Source of fodder & 0.00335 & 0.48578 & 0.0876 \\
Breed of dairy cattle kept & $\mathbf{0 . 3 5 8 5 7}$ & -0.13596 & 0.16759 \\
Adaptability of cattle & $\mathbf{0 . 4 1 6 6 9}$ & -0.02004 & 0.05866 \\
breeds to local conditions & -0.02068 & 0.13988 & $\mathbf{0 . 8 5 6 1 9}$ \\
Number of dairy cattle kept & -0.086 & -0.42337 & $\mathbf{0 . 3 4 2 0 9}$ \\
Main source of farm labour & 0.00823 & $\mathbf{0 . 5 2 3 7 2}$ & 0.17774 \\
\hline Income trend from dairying & & & \\
\hline
\end{tabular}

The factors being regression coefficients used to estimate the individual scores per case or row, as presented in Table 8 indicate that, the farming type practiced, production method employed, breed of dairy cattle kept, and a consideration of the adaptability of the dairy cattle kept to the local conditions are all related to Mixed Farming (Factor 1). Source of fodder and the observed trend in income from sale of milk from smallholder dairying are all related to Non-intensive production system (Factor 2). On the other hand, the number of dairy cattle kept and the main source of farm labour are all related to Own fodder (Factor 3).

\subsubsection{Establishing Whether Farmer's Adaptation to Climate Change Are Significant}

To establish the level of adaptation of the smallholder dairy farmers of Migori to Climate change, In-silico Z-score calculator was used to run one proportion Z-test for each of the eight parameters defined to measure adoption; with sample 1 being 0.5 (the assumed adoption level) and sample 2 being the \% of respondents adopting the various adaptive practices. Findings are presented in Table 9.

The results indicate that for each of the 8 parameters for measuring adaptation, the two sample means (that of the assumed adoption level and the actual adoption level) were significantly different, hence; the smallholder dairy farmers of Migori were generally highly adapted to climate change effects. The highest significant difference was experienced with respect to practicing mixed crop and dairy farming ( $\mathrm{Z}=17.82$; C.I: $0.449-0.551 ; \mathrm{p}<0.05)$, while the lowest significant difference was that for increased trend in income from dairy enterprise $(\mathrm{Z}=$ 7.05; C.I: 0.449 - 0.551; $\mathrm{p}<0.05)$.

\section{Discussions}

Mixed crop and livestock farming reported in Figure 3 could be attributed to an attempt by the study respondents to adapt to feed shortages. In this way, the crops and crop residues could supplement dairy animal feeds, even as the 
Table 9. In-silico Z-scores for level of adaptation of study respondents to climate change effects $(n=367)$.

\begin{tabular}{cccc}
\hline Parameter for measuring adoption (x) & \% Adopting & Z-Score & $\begin{array}{c}\text { C.I. } \\
\text { (95\% level of } \\
\text { significance) }\end{array}$ \\
\hline Mixed Crop \& Dairy Farming & 96.5 & 17.82 & $0.449-0.551$ \\
Non-Intensive Dairy Production Method & 95.1 & 17.28 & $0.449-0.551$ \\
Own Fodder & 92.4 & 16.25 & $0.449-0.551$ \\
Non Pure Breeds of Dairy Cattle & 87.7 & 14.44 & $0.449-0.551$ \\
Ayrshires, Guernseys, Jerseys \& Their Crosses & 87.5 & 14.37 & $0.449-0.551$ \\
2 Dairy Cattle \& Above & 92.9 & 16.44 & $0.449-0.551$ \\
Household Is Main Source of Farm Labour & 94.6 & 17.09 & $0.449-0.551$ \\
Increased Trend in Income from Dairy Enterprise & 68.4 & 7.05 & $0.449-0.551$ \\
\hline
\end{tabular}

manure from the dairy farm is used to improve soil fertility, hence; crop productivity. These findings are consistent with several findings of similar studies done across the Sub Saharan Africa [7] [19], but differ from those by Wamalwa [20] who established that most smallholder farmers adapted to climate change by diversifying out of agriculture. Mixed crop and livestock farming could also be attributed to an attempt by the study respondents to spread out risks of total loss from production, ensure sustainability in business, complementarity of enterprises (crop and livestock), increases in household income; and reduction in the overall production cost, as was argued out by Somda, J. et al. [21].

Non-intensive dairying practiced by majority of the study findings as reported in Figure 3 could be attributed to an attempt to achieve an efficient utilization of scarce feed resources, give the farmer flexibility to engage in other activities, reduce labour demand, reduce cost of parasite and disease control in the farm, and ensure efficient utilization of farm by-products. This is consistent with findings by Ketema \& Tsehay [5] regarding dairy production systems in Ethiopia.

While most of the study respondents kept non-pure breeds (i.e. crossbred dairy cattle) in an effort to adapt to parasites and diseases, Quddus [22] found that only some $35 \%$ of farmers in Bangladesh reared crossbred cattle as an adaptation to climate change. This suggests that probably in Bangladesh, the smallholder dairy farmers have better control of diseases and parasites compared to their Kenyan counterparts.

Figure 3 further indicated that the smallholder dairy farmers are generally rearing Ayrshires and Guernseys and their crosses for their tolerance to the high temperatures and diseases and parasites, as opposed to Friesians that used to be very common in the early days. This finding is consistent with findings by Kirui [23] that there was an increase in tick-borne diseases and pneumonia in Kosirai, Kenya where remarkable climate changes had been experienced in 10 years (2003-2013) compared to Namayumba, Uganda that had experienced climate change. 
Study respondents also established own fodder (Figure 3) in order to ensure sustainable feed availability to the dairy cattle, and the acreage of own feed was used to determine the number of dairy cattle kept. Other than depending on traditional fodder crop (Napier grass), respondents diversified feed sources (including Boma Rhodes grass, desmodium, sweet potato vines, Bracheria, chopped maize stover treated with molasses and other improved Napier grass cultivars) and practiced more dry feeding rather than wet feeding. Other than limited land sizes, low income base, ignorance, poor extension contact, and long distances to nearest feed stockists were some of the factors that limited study respondents from having sustainable access to high quality cattle feeds. This has the effect of compromising the breeding of the dairy cattle, thereby elongating the calving interval. These findings are consistent with that of Maleko et al. [24] that own-fodder provide the main feed source $(73 \%)$ for smallholder dairy farmers of Western Usamabra Highlands in Tanzania; and by Moran, J. [25] that feed shortages remains a major constraint in smallholder dairy farming, with feed costs making for $50 \%-60 \%$ of total cost of milk production.

The respondents indicated that labour demand has tended to increase over time as they endeavoured to adapt to climate change effects. This finding was corroborated by Morton [26]; Hassan \& Nhemachena [7]; and Wamalwa [20], strongly suggesting that availability of labour may strongly determine diversification of farming from monoculture to mixed cropping and mixed crop and livestock farming systems. Respondents coped with the labour shortages by relying more on household labour, reducing the herd size to 2 dairy cattle, and hiring extra labour at peak periods. Use of family labour to mitigate labour shortage was also established by Hassan \& Nhemachena [7]; Wamalwa [20], and Amuge \& Osewe [27]; with a significant relationship being established between large family sizes and smallholder farmers divesting from monoculture into mixed crop and dairy farming systems as an adaptive strategy to climate change (Hassan and Nhemachena, 2008). These findings, however, contradict those by Kasulo et al. [28] and Tripathi \& Mishra [29] who concluded that dairy farmers either did not perceive climate change as an immediate problem, or did, but took only implicit measures to adapt to climate change. Reduction of herd size to 2 dairy cattle was also established by Kirui [23] who found some $34 \%$ of her study respondents in Kosirai kept $1-2$ dairy cattle, while nearly half kept $2-5$ dairy cattle.

Figure 3 further indicated that majority of the study respondents had experienced an increase in income from the dairy enterprise over the past ten (10) years. This finding corroborates that of Shikuku et al. [30] that prioritized climate-smart livestock technologies in rural Tanzania. Shikuku et al. [30] indicated that both households with local cows and those with improved cows had increased income and food security.

Findings from qualitative study indicated that productivity of the animals has shown a general decline, with an ever-increasing milk demand. This has pushed 
milk prices up, making most dairy farmers to experience a general increasing trend in returns from dairying. Milk production has declined. There has been increase in calf pneumonia and increasing cases of silent heat due to poor management (lack of mineral supplementation and delays in accessing A.I. services that have since been privatized and the few available A.I. service providers are overwhelmed), although generally increases in temperature have meant more pronounced heat signs and aggressive animals when on heat.

The study established that mixed farming, non-intensive dairy production system and establishing own farm fodder were three factors that greatly determined the adaptability of smallholder dairy farmers to climate change in the study area. Thus, the farming type practiced, production method employed, breed of dairy cattle kept, and a consideration of the adaptability of the dairy cattle kept to the local conditions are all related to the practice of mixed farming. Similarly, smallholder dairy farmers' source of fodder and the observed trend in income from sale of milk from smallholder dairying are all related to the practice of non-intensive dairying; while the number of dairy cattle kept and the main source of farm labour are all related to the practice of establishing own farm fodder.

While from Z-score analyses, Migori smallholder dairy farmers are well adapted to climate change effects, Amuge \& Osewe [27] found the level of feed based technologies among smallholder dairy farmers of Ekerenyo Sub-county were unsatisfactory, similar to findings by Olumba \& Rahji [31] concerning adoption of improved plantain technologies in Anambra State, Nigeria.

\section{Conclusion}

Climate changes have taken place in the study area, with moderate to high effects on the performance of the smallholder dairy industry in Migori County. Migori smallholder dairy farmers are, however, significantly and positively adapted to climate change effects, hence; are more likely to increase productivity, sustain production and income from the dairy enterprise, and remain in the market for quite some time if the Government and other stakeholders provide the much-needed external support in terms of infrastructure, institutional and legal support. Despite the high level of adaptation of Migori smallholder dairy farmers to climate change effects, there is a need for stronger research-extension-farmer linkages so that latest findings from research could reach smallholder dairy farmers in time, and feedback from the dairy farmers could reach researchers in time. Government extension service having been liberalized and adopting a demand-driven group approach, civil society organizations, private players, research institutions and universities need to step up their farmer advisory services to bridge the gap in terms of limited farmer contact with extension and advisory service agents. This is more particularly important, considering the general reduction in employment of extension agents by the government and poorly remunerated and motivated extension agents within the civil service. 


\section{Acknowledgements}

We are grateful to the National and County Government of Kenya staff and staff of KALRO-Kisii, who participated in the research and made significant contribution as key informants. We are also very grateful to farmer groups, groups of elders (aged 60 years and above) from Kuria and Luo community, and Rongo Dairy Farmers' Cooperative Group, who participated in the Focus Group Discussions.

\section{Conflicts of Interest}

The authors declare no conflicts of interest regarding the publication of this paper.

\section{References}

[1] CBK (2007) Central Bank of Kenya. Annual Report, Government of Kenya, Nairobi.

[2] Bebe, B.O. (2003) Herd Dynamics of Smallholder Dairy in Kenya Highlands. PhD Thesis, Wageningen Agricultural University, Wageningen.

[3] Muho, J.M., Ngaira, K.W. and Ogindo, H.O. (2011) Living with Drought: The Case of Maasai Pastoralist of Northern Kenya. International Research Journals, 2, 779-789.

[4] FAO (1997) Report on the 1990 World Census of Agriculture: International Comparison and Primary Results by Country (1886-1995). Statistical Development Series 9, FAO, Rome.

[5] Ketema, H. and Tsehay, R. (1992) Dairy Production System in Ethiopia.

[6] ICARDA/CCAFS (2012) Strategies for Combating Climate Change in Drylands Agriculture. Synthesis of Dialogues and Evidence Presented at the International Conference on Food Security in Dry Lands, Doha, Qatar, November 2012. International Center for Agricultural Research in the Dry Areas (ICARDA) and Research Program on Climate Change, Agriculture and Food Security (CCAFS).

[7] Hassan, R. and Nhemachena, C. (2008) Determinants of African Farmers' Strategies for Adapting to Climate Change: Multinomial Choice Analysis. African Journal of Agricultural Research and Extension, 2, 83-87.

[8] GoK (2013a) Brief of Migori County. Agriculture Sector Development Support Programme (ASDSP), Migori.

[9] UNDP (2012) United Nations Development Programme. Climate Risk Management Report, November 2012. Climate Risks, Vulnerability and Governance in Kenya: A Review.

[10] GoK (2013b) Migori County Integrated Development Plan, 2013-2017. Government of Kenya, Nairobi.

[11] NebGuide (2012) My Plate: Dairy Group. University of Nebraska-Lincoln Extension, Institute of Agriculture and Natural Resources, IANR University of Nebraska, Linkoln.

[12] Yamane, T. (1967) Statistics: An Introductory Analysis. 2nd Edition, Harper and Row, New York.

[13] GoK (2012a) Annual Report for Rongo District. Ministry of Livestock Development, Livestock Production Department, Rongo.

[14] GoK (2012b) Awendo District Annual Report. Ministry of Livestock Development, Department of Livestock Production, Awendo. 
[15] GoK (2012c) Uriri District Annual Report. Ministry of Livestock Development, Department of Livestock Production, Uriri.

[16] GoK (2012d) Migori District Annual Report for the year 2012. Ministry of Livestock Development, Department of Livestock Production, Migori.

[17] GoK (2012e) Kuria West District Annual Report for the Year 2012. Ministry of Livestock Development, Department of Livestock Production, Kehancha.

[18] LVOS (2013) Lake Victoria Observing System. In: Milewa, P.A., Ed., Introduction to Climate Change-Conveying Climate Change Information to Rural Population, Highrise Printers and Lama Agencies, Rapogi, 18-30.

[19] Bagamba, F., Bashasha, B., Claessens, L. and Antle, J. (2012) Assessing Climate Change Impacts and Adaptation Strategies for Smallholder Agricultural Systems in Uganda. African Crop Science Journal, 20, 303-316.

[20] Wamalwa, J.W. (2015) Determinants of Smallholder Maize Farmers' Adaptation Strategies to Climate Change in Bahati Sub-County, Nakuru County, Kenya. Unpublished MA Research Project, University of Nairobi, Nairobi.

[21] Somda, J., Kamuanga, M., Münstermann, S., Keita, K. and Mendes, A. (2004) Characteristics of the Smallholder Dairying Farmers in West African Countries: Economic Viability and Paths for Improvement. Socio-Economic Research Working Paper No 2. ITC (International Trypanotolerance Centre), Banjul, 55 p.

[22] Quddus, M.A. (2012) Adaptation of Dairy Farming Technologies by Small Farm Holders: Practices and Constraints. Bangladesh Journal of Animal Science, 41, 124-135.

https://doi.org/10.3329/bjas.v41i2.14132

[23] Kirui, J.W. (2014) Assessment of the Influence of Climate Change on Smallholder Dairy Productivity in Kosirai, Kenya and Namayumba in Uganda. Unpublished M.Sc. Thesis, University of Nairobi, Nairobi.

[24] Maleko, D., Ng, W.T., Msalya, G., Mwilawa, A., Pasape, L. and Mtei, K. (2018) Seasonal Variations in the Availability of Fodder Resources and Practices of Dairy Cattle Feeding among the Smallholder Farmers in Western Usambara Highlands, Tanzania. Tropical Animal Health Production, 50, 1653-1664. https://doi.org/10.1007/s11250-018-1609-4

[25] Moran, J. (2005) Tropical Dairy Farming: Feeding Management for Smallholder Dairy Farmers in the Humid Tropics. Landlinks Press, Collingwood, 312 p. https://doi.org/10.1071/9780643093133

[26] Morton, J.F. (2007) The Impact of Climate Change on Smallholder and Subsistence Agriculture. Natural Resources Institute, University of Greenwich, Kent. https://doi.org/10.1073/pnas.0701855104

[27] Amuge, M.L. and Osewe, D.O. (2017) Socio-Economic Factors Influencing Adoption of Feed Based Dairy Technologies among Smallholder Farmers in Ekerenyo Sub-County, Kenya. Asian Journal of Agricultural Extension, Economics and Sociology, 16, 1-8. https://doi.org/10.9734/AJAEES/2017/32357

[28] Kasulo, V., Chikagwa-Malunga, S., Chagunda, M. and Roberts, D. (2012) The Perceived Impact of Climate Change and Variability on Smallholder Dairy Production in Northern Malawi. African Journal of Agricultural Research, 7, 4830-4837. https://doi.org/10.5897/AJAR12.259

[29] Tripathi, A. and Mishra, A.K. (2017) Knowledge and Passive Adaptation to Climate Change: An Example from Indian Farmers. Journal of Climate Risk Management, 16, 195-207. https://doi.org/10.1016/j.crm.2016.11.002

[30] Shikuku, K.M., Valdivia, R.O., Paul, B.K., Mwongera, C., Winowiecki, L., Laderach, 
P., Herrero, M. and Silvestri, S. (2017) Prioritizing Climate-Smart Livestock Technologies in Rural Tanzania: A Minimum Data Approach. Agricultural Systems Journal, 151, 204-206. https://doi.org/10.1016/j.agsy.2016.06.004

[31] Olumba, C.C. and Rahji, M.A.Y. (2014) An Analysis of the Determinants of the Adoption of Improved Plantain Technologies in Anambra State, Nigeria. Journal of Agriculture and Sustainability, 5, 232-245. 